Bulletin d'Histoire Contemporaine de I'Espagne

$54 \mid 2020$

Les espaces du politique dans l'Espagne du Trienio liberal (1820-1823)

\title{
El patrimonio bancario y artístico cultural vasco durante la Guerra Civil Española. Incautaciones, evacuaciones, embargos y pleitos
}

Julen LEZAMIZ LUGAREZARESTI

\section{CpenEdition}

\section{Journals}

Edición electrónica

URL: http://journals.openedition.org/bhce/3083

DOI: $10.4000 /$ bhce.3083

ISSN: 1968-3723

Editor

Presses Universitaires de Provence

Edición impresa

Fecha de publicación: 1 enero 2020

ISSN: 0987-4135

\section{Referencia electrónica}

Julen LEZAMIZ LUGAREZARESTI, «EI patrimonio bancario y artístico cultural vasco durante la Guerra Civil Española. Incautaciones, evacuaciones, embargos y pleitos », Bulletin d'Histoire Contemporaine de I'Espagne [En línea], 54 | 2020, Publicado el 01 julio 2020, consultado el 30 diciembre 2020. URL

http://journals.openedition.org/bhce/3083 ; DOI : https://doi.org/10.4000/bhce.3083

Este documento fue generado automáticamente el 30 diciembre 2020.

Bulletin d'histoire contemporaine de l'Espagne 


\title{
El patrimonio bancario y artístico cultural vasco durante la Guerra Civil Española. Incautaciones, evacuaciones, embargos y pleitos
}

\author{
Julen LEZAMIZ LUGAREZARESTI
}

\section{NOTA DEL EDITOR}

Tesis doctoral defendida el 21 de enero de 2016 en el Departamento de Historia Contemporánea de la Universidad del País Vasco. Director: Ricardo Miralles Palencia (U. del País Vasco). Tribunal: Presidente: José Luis de la Granja Sainz (U. del País Vasco). Secretario: Pedro Barruso Barés (IES Antonio Machado. Vocales: José Manuel Azcona Pastor (U. Rey Juan Carlos), José Miguel Delgado Idarreta (U. de La Rioja) y Santiago de Pablo Contreras (U. del País Vasco).

1 Miles de cajas que contenían el patrimonio bancario y artístico cultural incautado por el Gobierno provisional de Euzkadi durante la Guerra Civil española, fueron evacuadas de Bilbao en barcos mercantes británicos con destino a Francia, Holanda e Inglaterra durante 1937, antes de que la ciudad fuera tomada por las tropas franquistas. Todo este patrimonio evacuado de territorio republicano vasco sería embargado por las autoridades de Francia, Holanda y Gran Bretaña con motivo de las denuncias internacionales interpuestas por entidades y particulares relacionados con las autoridades franquistas. Lo que esta tesis doctoral investigó y analizó fueron hechos relevantes de la historia política y económica del País Vasco, tales como las apropiaciones de bienes públicos y privados llevados a cabo durante la Guerra Civil por las Juntas de Defensa de Vizcaya y Guipúzcoa y por el Gobierno provisional de Euzkadi. La finalidad que se pretendía era tratar un tema interesante y poco conocido, 
especialmente en lo que se refería a las provincias que conformaron el Frente Norte republicano vasco.

De esta forma, solamente la pregunta sobre lo que había ocurrido con el patrimonio vasco durante la Guerra Civil española daba origen a esta tesis doctoral, y, por lo tanto, la única respuesta era dar a conocer lo que sucedió entre los años 1937 y 1940. La línea de investigación se basó en los siguientes parámetros: a) la recogida de información relativa a la proveniencia del patrimonio vasco, compuesto por su patrimonio artístico (en su mayoría obras de arte, objetos religiosos y libros antiguos) y bienes materiales (valores, joyas, oro, plata, billetes, monedas y documentación de bancos, entidades de crédito, empresas y particulares); b) la incautación de este patrimonio por parte del Gobierno provisional de Euzkadi y su evacuación de territorio vasco republicano en barcos mercantes británicos; c) el traslado del mismo a Francia y Holanda y los posteriores embargos de que fue objeto por parte de las autoridades de ambos países a raíz de los pleitos derivados de las denuncias internacionales; d) las resoluciones judiciales, la situación en la que se encontraba el Gobierno de Euzkadi al finalizar la guerra y la vuelta del patrimonio vasco a territorio español, todo ya bajo control del régimen de Franco.

3 La tesis fue dividida en capítulos, con contextualización, desarrollo analítico e interpretativo y conclusiones, mostrando lo relativo al estado de la cuestión, la concepción y el desarrollo de la investigación, los análisis realizados, los resultados obtenidos, las conclusiones que se derivaron y algunas propuestas de mejora.

Desde el inicio de la Guerra Civil española, en el territorio bajo control de la República la falta de inversión en valores públicos fue una constante, mientras que los valores privados sufrieron una paralización absoluta y la toma de participación de los bancos se redujo a su mínima expresión. De esta forma, las peticiones de crédito por parte de organismos populares al Gobierno republicano se transformaron durante la guerra en incautaciones, desde el momento en que estos organismos populares se hicieron con el poder en zonas concretas que escapaban a la legalidad gubernamental.

5 Se pueden catalogar cuatro tipos de incautación efectuados por los republicanos durante la Guerra Civil:

6 a) Incautación del oro del Banco de España en Madrid y sus sucursales, incluyendo las de Bilbao y San Sebastián.

b) Incautación mediante la Caja de Reparaciones. En su afán por buscar la mayor compensación en posibilidades económicas, el hecho de incautarse de la riqueza mueble ocasionó múltiples y complejos problemas a la República relacionados con la reparación de los daños y perjuicios derivados de la Guerra Civil. Para ello, el Gobierno republicano ideó una forma de centralizar toda la riqueza mueble, creando por decreto del Ministerio de Hacienda del 23 de septiembre de 1936 la Caja de Reparaciones, que nacía como un organismo de nueva creación que tenía entre sus numerosas funciones la de recibir toda clase de bienes procedentes de incautaciones, retenciones o intervenciones por parte de los gobernadores civiles y de los comités provinciales del Frente Popular. Una zona del territorio republicano en la cual la Caja de Reparaciones no tuvo ningún control fue en el País Vasco. Desde que comenzara la rebelión, las Juntas de Defensa de Vizcaya y de Guipúzcoa comenzaron con las incautaciones de bienes pertenecientes tanto a personas jurídicas como naturales involucradas en el 
alzamiento militar. Días antes de la entrada de las tropas franquistas en San Sebastián en

8 septiembre de 1936, la Junta de Defensa de Guipúzcoa trasladó todo el patrimonio económico de la Banca guipuzcoana a Bilbao. Con la pérdida de Guipúzcoa, la Junta de Defensa de Vizcaya continuó con las incautaciones y con la apertura de expedientes hasta la llegada del Gobierno provisional de Euzkadi en octubre de 1936, que propició la creación de una Junta Calificadora Central.

9 c) Incautación de bienes particulares depositados en el Banco de España y en la Banca privada. Desde el comienzo de la guerra en todas las zonas republicanas, no sólo por parte del Gobierno republicano, sino también por los Gobiernos catalán y vasco, y por los Consejos santanderino y asturiano, y en todas sus entidades bancarias privadas: Banco Hispano Americano, Banco de Bilbao, Banco de Vizcaya, Banco de Comercio, Anglo South American Bank, Crédit Lyonnais, Banco Guipuzcoano, Internacional Banking, Monte de Piedad, Banco de Aragón, Banco Aragonés de Crédito, Banco de Valencia, Banco Español de Crédito, Banco Central, Banco de Santander, Banco Mercantil, Banco de Gijón y Banco Asturiano. Aparte de la confiscación de las reservas metálicas del Banco de España, las autoridades republicanas procedieron de modo sistemático a la confiscación del dinero, divisas, valores y efectos de propiedad de particulares que existían en depósito y en paquetes lacrados en la Banca privada. Para ello se dictaron disposiciones conminatorias, como los decretos del 3, 10 y 16 de octubre de 1936, que obligaron a la Banca privada a entregar sus remesas de pesetas oro, aparte de gran cantidad de libras, francos y otras monedas extranjeras. Para el caso vasco, el Gobierno de Euzkadi decretó incautaciones de todos los bienes que las personas afectas a la causa de los sublevados poseían en las cajas de seguridad, ordenando así mismo el traspaso de los saldos de sus cuentas a la cuenta del Departamento de Hacienda del Gobierno vasco. Se incautó del oro, alhajas y valores extranjeros depositados en las cajas de seguridad de las entidades bancarias, y los perjuicios causados podrían catalogarse como requisas e incautaciones. Dentro de las requisas figuraba la incautación de efectos pignorados y en depósito en los bancos, especialmente el de todo el oro amonedado o en pasta que figuraba en los lotes respectivos, y se practicaron valiéndose de órdenes emanadas de las diversas dependencias del Gobierno vasco y contra abono de su importe. Los bienes más preciados por el Gobierno vasco dentro de los bancos eran los valores extranjeros y de cotización internacional, cuyos intereses se pagaban en oro o en divisas. A la incautación de bienes particulares que estaban en las cajas de seguridad bancarias, habría que añadir también los bienes inmuebles expropiados forzosamente a personas desafectas a la República, así como las multas en dinero por diversos delitos, como el de la apropiación indebida de oro y plata amonedado y alhajas, todo esto llevado a cabo por el Departamento vasco de Gobernación y su servicio de Seguridad y Orden Público.

10 d) Incautación del patrimonio artístico cultural. Sobre la incautación del patrimonio artístico cultural en museos, Diputación, edificios oficiales, Ayuntamientos, iglesias, edificios religiosos, archivos y bibliotecas. Durante los meses que duró la guerra en Vizcaya, y sobre todo con la ofensiva nacional en marzo de 1937, la Dirección General de Bellas Artes, Archivos y Bibliotecas, dependiente de la Consejería de Justicia y Cultura dirigida por Jesús María Leizaola, realizó una elección de lugares como refugio para los tesoros artísticos, recogiendo las obras de arte, documentos históricos y 
culturales que se encontraban en zona de guerra y en los pueblos situados en el frente de batalla.

11 Una de las primeras utilizaciones del tráfico marítimo durante la contienda con la finalidad de evacuar bienes tuvo lugar cuando el ministro de Hacienda, Juan Negrín, según el decreto reservado del 13 de septiembre de 1936 y firmado por Manuel Azaña, presidente de la República, asumía la custodia de las reservas metálicas de oro y plata del Banco de España y decretaba sus salidas, dando una apariencia legal a la incautación y haciendo entender que, al ser propiedad del Banco de España, solamente se trasladaba a otro lugar para mejorar su custodia. El traslado de las reservas de oro y plata se llevó a cabo en camiones desde el Banco de España hasta la estación de Atocha en Madrid el 15 de septiembre de 1936, y desde allí hasta Cartagena en un tren especial. Entre los días 22 y el 25 de octubre desde los polvorines de La Algameca fueron embarcadas 510 toneladas de oro en 7.800 cajas de 75 kilos cada una en los buques soviéticos Kine, Kursk, Neva y Volgoles, con destino al puerto de Odessa en la URSS. La razón más esgrimida a favor de este traslado del oro español al extranjero siempre estuvo motivada por los gastos de guerra del Gobierno republicano, rechazada por las autoridades franquistas que intentaron probar durante el conflicto cómo todos los gastos de guerra podían ser compensados con las exportaciones de productos españoles.

12 La importante decisión geoestratégica del alto mando militar franquista que derivó en el bloqueo naval franquista al Frente Norte republicano a comienzos de 1937, dio lugar al protagonismo de los Blockade Runners, mercantes extranjeros, en su mayoría británicos, que lograron burlar dicho bloqueo para poder abastecer de suministros y armas al bando republicano. El Gobierno provisional de Euzkadi, a su vez, hizo utilización de estos mercantes rompedores del bloqueo para realizar sus transacciones comerciales con el extranjero, evacuar personas de todas las edades a varios países europeos y transportar secretamente toda la riqueza bancaria y artística cultural que había incautado y expropiado en su territorio. La imparable ofensiva militar comenzada por Franco el 31 de marzo de 1937 sobre Vizcaya, provocó la decisión del Gobierno vasco, por medio del decreto emitido el 3 de mayo, de incautarse y expropiarse de la totalidad de los bienes situados en las cajas de seguridad de la Banca vasca.

El 21 de mayo de 1937, en previsión de la caída de Bilbao, las autoridades del Gobierno vasco ordenaban cargar a bordo del mercante británico Joyce Llewelyn 7.293 cajas con oro, valores y la riqueza de todos los bancos y cajas de ahorro de Vizcaya, de Guipúzcoa y de sus sucursales del Banco de España, además del tesoro artístico vizcaíno. Fletado por el Gobierno vasco, el 22 de mayo el Joyce Llewelyn llegaba a La Pallice, cambiando por conveniencia su nombre por el de Seabank. Su capitán tenía que esperar a recibir instrucciones. El 12 de junio 2.065 cajas con similar riqueza embarcadas en el mercante británico Thurston llegaban al puerto francés de La Pallice.

En la madrugada del 13 de junio zarpaba de Bilbao hacia Burdeos otro vapor británico, el Thorpehall, con 30 cajones repletos de joyas y alhajas. El 16 de junio las 2.065 cajas del Thurston eran trasbordadas al Seabank, acogiendo éste en sus bodegas 9.358 cajas con los archivos del Gobierno de Euzkadi, oro, depósitos y fondos económicos de los Bancos de todo el territorio republicano vasco. El 22 de junio la delegación vasca en Bayona ordenaba transbordar las cajas del Seabank al barco de bandera española Axpe Mendi, bajo control del Gobierno de Euzkadi. El día 25 de junio, mientras se transbordaba la carga, las autoridades francesas ordenaron la entrada de los dos 
mercantes en puerto, quedando confiscado su cargamento mientras se tramitaba una reclamación sobre su propiedad interpuesta por varios bancos españoles. Los mercantes fueron retenidos en puerto pendientes del resultado ante los tribunales franceses, para determinar la propiedad legal de los bienes.

Mientras tanto, el Thorpehall, en vista de la postura tomada por las autoridades francesas, abandonaba el 27 de junio Burdeos con destino a Flesinga en Holanda, con un destructor británico dándole protección y escoltándole hasta que saliera de puerto. Días antes de la entrada de las tropas franquistas en Bilbao, a primeros de junio del 37, los representantes oficiales del Gobierno rebelde se habían entrevistado en Hendaya con el encargado de Negocios Extranjeros de Gran Bretaña, sir Henry Chilton, para exponer una enérgica protesta por el hecho de que, bajo el pretexto de la evacuación civil de Bilbao, se estaba llevando a cabo un escandaloso saqueo de valores, joyas y efectos de valor existentes en Vizcaya por parte del Gobierno vasco, que hacía escoltar este tesoro en los mercantes británicos puestos bajo la protección de la escuadra de guerra de su majestad británica.

Las autoridades santanderinas y asturianas utilizaron el mismo sistema para sacar todo su patrimonio de zona republicana. El 23 de septiembre de 1937 salía de Gijón el mercante británico Mydol con una carga de 1.098 cajas con alhajas, plata y valores, más 124 cajas con el patrimonio artístico de Santander y Asturias y una gran caja con 79 lingotes de plata y 13 planchas de plata, arribando al puerto francés de Le Havre el 30 de septiembre.

De esta forma, un aspecto más desconocido de la utilización y el uso de mercantes tanto españoles como extranjeros por parte de las tres autoridades republicanas norteñas, el Gobierno provisional de Euzkadi, la Junta de Santander y el Consejo Soberano de Asturias y León, como consecuencia del imparable avance de las tropas franquistas durante la ofensiva de 1937, fue el de conseguir sacar del Frente Norte todas las reservas monetarias, el oro, la plata, los valores y las alhajas depositadas en las entidades bancarias privadas y en las sucursales del Banco de España, así como los bienes de particulares y del patrimonio artístico, que habían sido incautados por estas autoridades e instituciones mencionadas. Aunque solamente fue una vez en el caso de la Junta de Santander y del Gobierno Soberano de Asturias, fueron varias veces en el caso del Gobierno provisional de Euzkadi, y donde más repercusiones internacionales captaron, sobre todo por el desconocimiento general que se tuvo de ellos en lo que respecta a la ingente cantidad de patrimonio incautado y transportado a países extranjeros, Francia y Holanda, y por las sentencias que dictaron los tribunales de estos países donde los juicios se llevaron a cabo.

18 Una gran cantidad de incautaciones de la riqueza mueble española cometida por el Gobierno de la Republica durante la Guerra Civil se perdió para siempre o no pudo ser rescatada después de la contienda, incluidas las existencias de oro trasladadas a la URSS. La evacuación del patrimonio de Asturias y Santander fue denunciada por las autoridades franquistas ante los tribunales franceses, los cuales embargaron la carga hasta resolverse la situación judicial. En este caso la sentencia de los tribunales en el pleito de Rouen dio la razón al Gobierno de la Republica como legítimo dueño de la carga, al haberse alzado en armas las autoridades rebeldes contra un gobierno legal como el republicano. A principios de 1938 el tesoro era transportado a la Embajada española en París. 

las incautaciones republicanas en la Guerra Civil, el ministro de Hacienda Fernando Méndez Aspe. El cargamento del Vita, compuesto de oro, joyas y diamantes, tuvo una función vital como instrumento de poder republicano en el exilio, aunque su destino a partir de la llegada a México se pierde en una nebulosa fruto de ambiciones personales y acusaciones mutuas aclaradas por fin a día de hoy. conocida e investigada de las realizadas en territorio republicano, la efectuada por el Gobierno provisional de Euzkadi, es la única que regresó intacta a España. En julio de 1937 Nicolás Vicario, registrador de la propiedad en Bilbao, presentó en el Juzgado de Guardia de la ciudad una denuncia contra el Gobierno de Euzkadi por el expolio y traslado al extranjero del casi total patrimonio de Vizcaya y Guipúzcoa que podía ascender a diez mil millones de pesetas. Los bancos españoles ya habían solicitado al Tribunal Civil de La Rochelle en Francia el embargo de las cajas del Seabank y del Axpe Mendi, y les fue concedido pese a la oposición de los capitanes de ambos mercantes. Apelaron los capitanes y las autoridades vascas al Tribunal de Apelación de Poitiers, compareciendo como coadyuvante de la apelación el Gobierno republicano de Valencia, aduciendo que todo lo que se hizo en Bilbao fue hecho por su Gobierno y para su Gobierno, y que el embargo debía ser levantado, porque los tribunales franceses no entendían en un litigio en que el Gobierno de la República se declaraba interesado.

A esto se unía el peligro que suponía la influencia política de elementos facciosos a funcionarios públicos franceses, demostrando la necesidad de que el Gobierno galo, por el hecho de adquirir una gran responsabilidad moral al hallarse gran parte del patrimonio en su territorio, fuera quien se preocupara de su seguridad y custodia, trasladándolo a un lugar más seguro que un depósito franco de un puerto. Pero un informe a favor de los bancos mostró que la pretensión del Gobierno republicano al alegar la inmunidad de jurisdicción de estados extranjeros no valía en este caso porque el Gobierno republicano había acudido espontáneamente a los tribunales franceses, sometiéndose a la jurisdicción francesa. El Tribunal de Apelación desestimó el recurso y confirmó el embargo.

Según fue pasando el tiempo las desavenencias judiciales entre el Gobierno vasco y el Gobierno de la República por hacerse con la legitimidad del inmenso patrimonio se fueron acrecentando. La victoria del segundo en el pleito de Rouen y sus consecuencias judiciales provocará el comienzo de las diferencias institucionales entre este Gobierno y el Gobierno provisional de Euzkadi por el control del patrimonio bancario y artístico cultural vasco en los pleitos que se estaban llevando a cabo en Francia y Holanda. Durante todo el año 1938 se intentará llegar a una solución negociada por parte de ambos Gobiernos y de sus instituciones de Hacienda para la resolución del conflicto surgido en torno al patrimonio vasco y su gran valor.

Pero los cambios que se habían producido en la guerra española, ya con la victoria de los franquistas, convencieron a la justicia francesa a dictar sentencias favorables a Franco. En agosto de 1939 el patrimonio vasco salía del puerto de La Rochelle con rumbo a Bilbao y según un expediente informativo del Departamento de Justicia del Gobierno provisional de Euzkadi en el juicio seguido por el Tribunal Civil de La Rochelle sobre los valores evacuados, el total en pesetas del cargamento ascendía a 6.498.000.000, aunque las autoridades francesas le calculaban casi el doble de valor debido a su revalorización durante el tiempo que había estado embargado. 
24 Respecto al patrimonio transportado por el Thorpehall, también los bancos españoles solicitarían el embargo de los bienes ante el Tribunal de Midelburgo en Holanda, rechazando la petición del Gobierno vasco y del republicano que solicitaban el alzamiento del embargo de las cajas. El tribunal aceptó la demanda de los bancos españoles, pero tanto el Gobierno vasco como el republicano apelaron contra esta decisión del tribunal. La apelación pasó al Tribunal de Apelación de La Haya, que dio la razón a los bancos. El intento por parte de la Compañía De Bruyne, representante y consignataria del mercante Thorpehall, de hacerse con el control de la defensa del pleito cuando ya finalizaba la Guerra Civil, llevará al Gobierno de Euzkadi, junto a otros motivos, a mantener una política de aplazamientos judiciales. Tras unos pleitos que duraron varios años, casi la totalidad de los cajones regresó a Bilbao, sin poder valorar el montante del patrimonio vasco embargado por su difícil cuantificación al estar compuesto por joyas y alhajas en su mayoría. 